\title{
Aspectos fisiológicos e microbiológicos de beterrabas minimamente processadas
}

\author{
Maria Carolina Dario Vitti(1), Ricardo Alfredo Kluge(1), Claudio Rosa Gallo(2), Marlene Aparecida Schiavinato ${ }^{(3)}$, \\ Celso Luiz Moretti( ${ }^{(4)}$ e Angelo Pedro Jacomino(5)
}

\begin{abstract}
(1)Universidade de São Paulo (USP), Escola Superior de Agricultura Luiz de Queiroz (Esalq), Dep. de Ciências Biológicas, Caixa Postal 9, CEP 13418-900 Piracicaba, SP. E-mail: mcdvitti@esalq.usp.br, rakluge@esalq.usp.br (2)USP-Esalq, Dep. de Agroindústria, Alimentos e Nutrição. E-mail: crgallo@esalq.usp.br (3)Universidade de Campinas, Instituto de Biologia, Dep. de Fisiologia Vegetal, Campinas, SP. E-mail: mschiavi@unicamp.br (4)Embrapa Hortaliças, Caixa Postal 218, CEP 70359-970 Brasília, DF. E-mail: celso@cnph.embrapa.br (5)USP-Esalq, Dep. de Produção Vegetal. E-mail: jacomino@esalq.usp.br
\end{abstract}

Resumo - O objetivo deste trabalho foi avaliar aspectos fisiológicos e microbiológicos de beterrabas minimamente processadas. A taxa respiratória e a produção de etileno foram avaliadas até quatro horas após o processamento e durante 10 dias de armazenamento a $5^{\circ} \mathrm{C}$. As análises microbiológicas foram realizadas no dia do processamento e após 10 dias de conservação. Raízes intactas apresentaram a menor taxa respiratória $\left(5 \mathrm{~mL} \mathrm{CO}_{2} \mathrm{~kg}^{-1} \mathrm{~h}^{-1}\right)$, enquanto beterrabas raladas e descascadas obtiveram taxa respiratória de $30 \mathrm{~mL} \mathrm{CO}_{2} \mathrm{~kg}^{-1} \mathrm{~h}^{-1}$ após quatro horas do processamento. Beterrabas minimamente processadas apresentaram um pico respiratório no segundo dia de armazenamento $\left(80 \mathrm{~mL} \mathrm{CO}_{2} \mathrm{~kg}^{-1} \mathrm{~h}^{-1}\right)$, estabilizando em $30 \mathrm{~mL} \mathrm{CO}_{2} \mathrm{~kg}^{-1} \mathrm{~h}^{-1}$ no quarto dia. Não foi detectado etileno em beterrabas intactas e descascadas ao passo que em beterrabas minimamente processadas, a produção de etileno nas primeiras horas após o corte atingiu $0,90 \mu \mathrm{L} \mathrm{kg}^{-1} \mathrm{~h}^{-1}$, registrando-se pouca variação ao longo das quatro horas de avaliação e durante o período de armazenamento a $5^{\circ} \mathrm{C}$. As contagens de bactérias psicrotróficas e coliformes totais mantiveram-se dentro dos limites aceitáveis, e não foi detectada presença de coliformes fecais e Salmonella.

Termos para indexação: Beta vulgaris, processamento mínimo, respiração, etileno, armazenamento.

\section{Physiological and microbiological aspects of fresh cut beet roots}

\begin{abstract}
The aim of this work was to evaluate physiological and microbiological aspects of fresh cut beet roots. Respiratory activity and ethylene evolution were evaluated during four hours after processing and during the storage period of ten days at $5^{\circ} \mathrm{C}$. Microbiological analysis was carried out right after processing and after ten days of storage. Intact roots showed the lower respiratory activity $\left(5 \mathrm{~mL} \mathrm{CO}_{2} \mathrm{~kg}^{-1} \mathrm{~h}^{-1}\right)$, whereas shredded and peeled beet roots presented a respiration rate of $30 \mathrm{~mL} \mathrm{CO}_{2} \mathrm{~kg}^{-1} \mathrm{~h}^{-1}$ four hours after processing. Fresh cut beet roots showed a peak during the second storage day $\left(80 \mathrm{~mL} \mathrm{CO}_{2} \mathrm{~kg}^{-1} \mathrm{~h}^{-1}\right)$, reducing to $30 \mathrm{~mL} \mathrm{CO}_{2} \mathrm{~kg}^{-1} \mathrm{~h}^{-1}$ at the fourth day. No ethylene evolution was detected in intact and peeled beet roots whereas in the fresh cut material it was observed in the first hours after processing, reaching $0.90 \mu \mathrm{L} \mathrm{kg}^{-1}{ }^{-1}$. Few variations were observed during the four-hour period after processing and during the refrigerated storage. Psychotrophic bacteria and total coliforms counts were within acceptable limits, and no Salmonella or fecal coliforms were detected.
\end{abstract}

Index terms: Beta vulgaris, fresh cut, respiration, ethylene, storage.

\section{Introdução}

O processamento mínimo é definido como qualquer alteração física causada em frutos ou hortaliças que mantém o estado fresco desses produtos. Inclui operações de seleção, lavagem, corte, sanitização, centrifugação, embalagem, armazenamento e comercialização (International Fresh-Cut Produce Association, 1999; Moretti, 1999).
As frutas e as hortaliças minimamente processadas mantêm seus tecidos vivos, porém não exibem a mesma resposta fisiológica que o tecido inteiro (Wiley, 1994). Estes produtos são mais perecíveis do que quando intactos, considerando que são submetidos a severos estresses físicos, provenientes, principalmente, do descascamento e do corte. Esses danos mecânicos aumentam o metabolismo, com conseqüente aumento da taxa respiratória e da síntese de etileno, causando maior 
velocidade de deterioração. O etileno proveniente do corte contribui para a biossíntese de enzimas envolvidas em alterações fisiológicas e bioquímicas associadas à senescência (Brecht, 1995).

O dano mecânico causado pelo corte ou descascamento é um dos maiores obstáculos na conservação dos produtos minimamente processados, e a taxa respiratória destes produtos é cerca de três a cinco vezes maior que a dos órgãos intactos (Chitarra, 1998). Chervin et al. (1992) observaram que a taxa respiratória de cenoura minimamente processada é o dobro da verificada em cenoura inteira nas primeiras quatro horas após o processamento ou até cinco vezes maior após 30-40 horas. Quanto ao pimentão minimamente processado, Moretti et al. (2000) verificaram que o material minimamente processado apresentava evolução de $\mathrm{CO}_{2}$ quatro vezes maior que o fruto intacto, ambos armazenados a $2^{\circ} \mathrm{C}$.

Mesmo os órgãos de reserva, como raízes, bulbos, rizomas e tubérculos, que naturalmente possuem uma vida pós-colheita relativamente longa quando submetidos ao processamento mínimo, passam a ser altamente perecíveis, com vida de prateleira muito curta (Kasmire \& Cantwell, 1992).

Adicionalmente, o processamento mínimo favorece a contaminação por microrganismos deterioradores e patogênicos, em razão do manuseio e do aumento dos danos aos tecidos (Wiley, 1994), o contrário do que ocorre com as frutas e hortaliças intactas, que são parcialmente protegidas da invasão microbiana pela casca (Shewfelt, 1986).

Este trabalho teve como objetivo avaliar aspectos fisiológicos e microbiológicos de beterrabas minimamente processadas.

\section{Material e Métodos}

As beterrabas, cv. Early Wonder, colhidas na região de Piracicaba,SP, foram levadas para o laboratório de Fisiologia e Bioquímica Pós-Colheita do Departamento de Ciências Biológicas da Esalq/USP, onde foram selecionadas quanto à firmeza (utilizaram-se raízes firmes) e ausência de danos mecânicos e infecção fúngica. Foram pré-lavadas em água corrente com o objetivo de retirar as impurezas vindas do campo. A seguir, o material foi separado em três lotes; dois deles foram minimamente processados e o outro permaneceu intacto.

As etapas de processamento mínimo ocorreram dentro da câmara a $10^{\circ} \mathrm{C}$ sobre mesa de aço inoxidável, devidamente higienizada. Os operadores utilizaram botas, aventais, luvas, máscaras e toucas, como parte das condições mínimas de assepsia. Um dos lotes minimamente processados foi apenas descascado e outro sofreu, além desta operação, o corte em retalhos.

As etapas de processamento foram as seguintes: descascamento, em que o produto foi descascado mecanicamente por descascadora industrial com disco abrasivo para retirada da película externa das raízes; lavagem, com raízes imersas em água resfriada $\left(5^{\circ} \mathrm{C}\right)$ por dois minutos para retirar o calor de campo, reduzindo, portanto, a atividade metabólica do produto; corte, em que as beterrabas foram cortadas em forma de retalhos com $2 \mathrm{~mm}$ de espessura, utilizando-se processadora industrial; sanificação, em que, após o corte, o material foi sanificado por seis minutos em água clorada (200 mg L $\mathrm{m}^{-1}$ de cloro ativo), com o objetivo de reduzir riscos de contaminação; enxagüe, com raízes enxaguadas por um minuto em água com $3 \mathrm{mg} \mathrm{L}^{-1} \mathrm{de}$ cloro ativo para a retirada do excesso de cloro; centrifugação, realizada em centrífuga doméstica durante um minuto para a retirada do excesso de umidade do produto, com velocidade constante equivalente a $800 \mathrm{~g}$; armazenamento, pelo acondicionamento das raízes durante 10 dias em bandejas de poliestireno expandido, ou seja, $150 \mathrm{~g}$ de produto dispostos por bandeja de $14 \times 20 \mathrm{~cm}$, envolvidos por filme de policloreto de vinila (PVC) com 14 micras de espessura e armazenados a $5 \pm 1^{\circ} \mathrm{C}$ e $85 \pm 5 \%$ UR.

$\mathrm{Na}$ avaliação da taxa respiratória, raízes intactas, descascadas e raladas foram acondicionadas em frascos de vidro herméticos de $600 \mathrm{~mL}$ durante uma hora e armazenadas a temperatura de $5^{\circ} \mathrm{C}$. Na tampa dos frascos foi colocado um septo de silicone através do qual foi retirada uma alíquota da atmosfera interna dos frascos $(2 \mathrm{~mL})$ e medida a taxa respiratória em um analisador de $\mathrm{CO}_{2}$. Os resultados expressos em porcentagem de $\mathrm{CO}_{2}$ foram utilizados no cálculo da taxa respiratória, levando-se em consideração o volume do frasco, a massa das beterrabas e o tempo em que o frasco permaneceu fechado. A cada hora, durante um período de quatro horas, foi retirada uma amostra da composição gasosa do interior dos frascos selados e mediu-se a evolução de $\mathrm{CO}_{2}$.

As leituras foram realizadas a cada dois dias, durante dez dias, somente nas beterrabas raladas. Os resultados foram expressos em $\mathrm{mL}$ de $\mathrm{CO}_{2} \mathrm{~kg}^{-1} \mathrm{~h}^{-1}$. O procedimento para determinação da taxa de produção de etileno foi 
semelhante ao utilizado na determinação da taxa respiratória. A taxa de produção de etileno foi obtida retirando-se, com auxílio de uma seringa, uma alíquota de $0,5 \mathrm{~mL}$ de amostra da composição gasosa do interior dos frascos selados e injetando-se em cromatógrafo a gás (Shimadzu GC 14-B). O gás de arraste foi o nitrogênio, a um fluxo de $20 \mathrm{~mL} \mathrm{minuto}^{-1}$. As temperaturas mantidas no aparelho foram de $80^{\circ} \mathrm{C}$ para a coluna, $100^{\circ} \mathrm{C}$ no injetor e $150^{\circ} \mathrm{C}$ no detector. Como padrão foi utilizado etileno puro $\left(1 \mu \mathrm{L} \mathrm{L}^{-1}\right)$, da White Martins. Os resultados foram expressos em $\mu \mathrm{L} \mathrm{kg}^{-1} \mathrm{~h}^{-1}$.

As análises microbiológicas foram realizadas no dia do processamento e no $10^{\circ}$ dia de armazenamento, somente para beterrabas raladas. A microbiota contaminante da beterraba minimamente processada foi avaliada pela contagem total de bactérias psicrotróficas, NMP de coliformes totais e fecais e presença/ausência de Salmonella. As análises para contagem de bactérias psicrotróficas, segundo o método convencional (PCA) e para o NMP de coliformes, segundo a Técnica de Tubos Múltiplos, foram realizadas conforme Vanderzant \& Splittstoesser (1992). Na determinação da presença de Salmonella foi empregado o Kit rápido '1-2 test', fabricado pela BioControl/USA, conforme Silva et al. (2001).

O delineamento experimental foi inteiramente casualizado com cinco repetições (150 g de produto). Os resultados das análises fisiológicas foram submetidos à análise da diferença mínima significativa em teste de comparações múltiplas, em que as diferenças entre dois tratamentos maior que a soma de dois desvios-padrões foram consideradas significativas a 5\% de probabilidade (Shamaila et al., 1992). Na avaliação dos aspectos microbiológicos, os resultados foram expressos em UFC $\mathrm{g}^{-1}$ de produto para bactérias psicrotróficas, NMP g ${ }^{-1}$ para coliformes totais e fecais e presença/ausência de Salmonella em $25 \mathrm{~g}$ de produto.

\section{Resultados e Discussão}

As raízes intactas apresentaram a menor taxa respiratória durante o período avaliado, atingindo valores próximos de $5 \mathrm{~mL} \mathrm{CO}_{2} \mathrm{~kg}^{-1} \mathrm{~h}^{-1}$ (Figura 1). Por sua vez, as raízes raladas apresentaram elevação significativa da atividade respiratória logo após o processamento mínimo, sendo seis vezes maior que as raízes intactas, atingindo valores próximos a $30 \mathrm{~mL} \mathrm{CO} \mathrm{Cg}^{-1} \mathrm{~h}^{-1}$. As beterrabas descascadas também tiveram uma elevação na atividade respiratória, sendo aproximadamen- te quatro vezes maior que as beterrabas intactas, até a terceira hora após o descascamento (Figura 1). Após quatro horas de armazenamento, não foi verificada diferença significativa na atividade respiratória entre as raízes descascadas e raladas. A respiração é o principal processo fisiológico envolvido em pós-colheita de produtos hortícolas, e quanto maior a atividade respiratória, menor é o tempo de conservação do produto. $\mathrm{O}$ descascamento e o corte efetuado nos produtos elevam a taxa respiratória dos mesmos por causa das reações fisiológicas e bioquímicas se tornarem mais ativas, em resposta ao estresse (Watada et al., 1990).

Resultados semelhantes foram observados em batatas, cujos tubérculos intactos apresentaram taxa de evolução de $\mathrm{CO}_{2}$ de $1,22 \mathrm{~mL} \mathrm{CO}_{2} \mathrm{~kg}^{-1} \mathrm{~h}^{-1} \mathrm{a} 2^{\circ} \mathrm{C}$; em batatas descascadas e fatiadas verificou-se uma taxa de $2,55 \mathrm{e}$ $6,1 \mathrm{~mL} \mathrm{CO}_{2} \mathrm{~kg}^{-1} \mathrm{~h}^{-1}$, respectivamente (Gunes \& Lee, 1997).

Arruda (2002) estudou a taxa respiratória do melão inteiro e minimamente processado armazenado a $3^{\circ} \mathrm{C} \mathrm{e}$ observou que imediatamente após o corte, a taxa respiratória sofreu incremento de aproximadamente três vezes em relação aos frutos inteiros e 24 horas após o processamento, a taxa respiratória assumiu valores se-

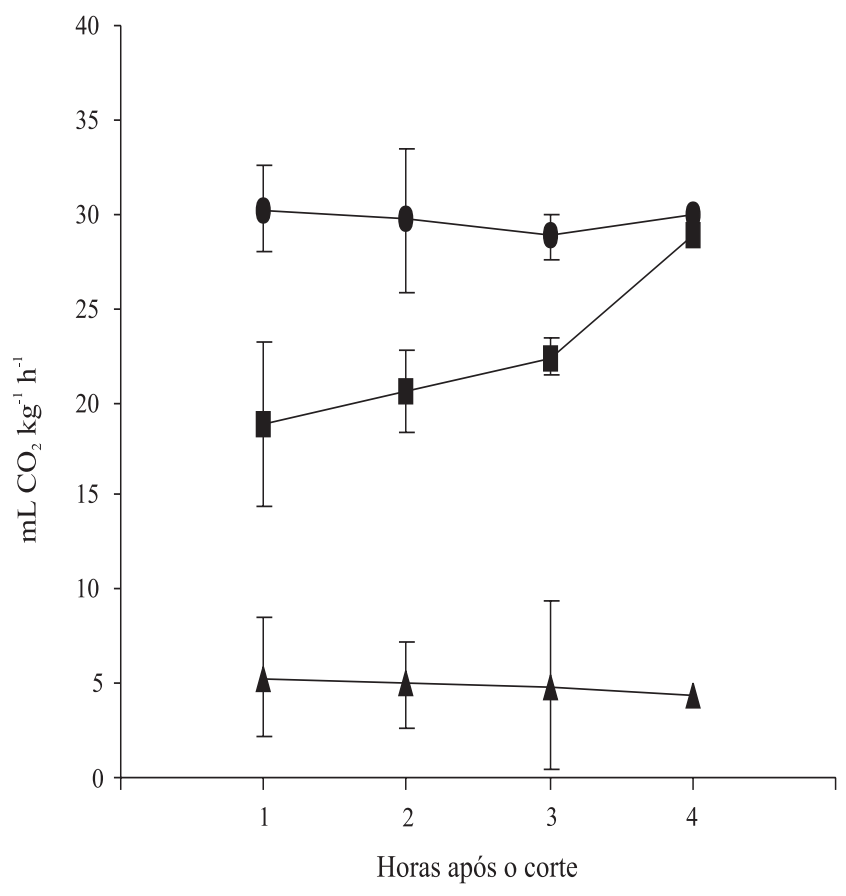

Figura 1. Taxa respiratória de beterrabas intactas $(\mathbf{\Lambda})$, descascadas $(\boldsymbol{\square})$ e raladas $(\boldsymbol{\cup})$ logo após o corte, armazenadas a $5 \pm 1^{\circ} \mathrm{C}$ e $85 \pm 5 \%$ UR. Barras verticais representam o desvio-padrão da média.

Pesq. agropec. bras., Brasília, v.39, n.10, p.1027-1032, out. 2004 
melhantes aos verificados antes do processamento.

As raízes raladas apresentaram maior taxa respiratória no segundo dia de armazenamento, ou seja, $77,59 \mathrm{~mL} \mathrm{CO}_{2} \mathrm{~kg}^{-1} \mathrm{~h}^{-1}$ (Figura 2). A partir do quarto dia verificou-se uma estabilização em valores próximos a $30 \mathrm{~mL} \mathrm{CO} \mathrm{kg}^{-1} \mathrm{~h}^{-1}$. Resultados similares foram registrados por López Osornio \& Chaves (1998), em beterrabas raladas e armazenadas a $0^{\circ} \mathrm{C}$.

O pico respiratório observado nas beterrabas minimamente processadas é oriundo do estresse provocado pelo corte o qual provoca uma perda da compartimentação celular e, com isto, os substratos do metabolismo respiratório entram em maior contato com os complexos enzimáticos resultando em aumento da taxa respiratória. A redução subseqüente na taxa respiratória das beterrabas minimamente processadas, a partir do quarto dia, é discutível. É possível que haja uma auto-regulação da atividade respiratória do tecido causada pela grande produção de ATP (Purvis, 1997). Outra hipótese é que esta redução da taxa respiratória ocorra pelo fato de os substratos respiratórios pararem de reagir com as enzimas presentes nas células da superfície de corte. Portanto, a taxa respiratória observada a partir do quarto dia pode ser resultante das células localizadas abaixo da superfície danificada pelo corte.

Não foi detectado etileno durante as quatro primeiras horas em beterrabas intactas e descascadas, e a produção de etileno gerada nestas condições é muito baixa, isto é, menor que $0,1 \mu \mathrm{L} \mathrm{kg}^{-1} \mathrm{~h}^{-1}$. Já nas beterrabas rala-

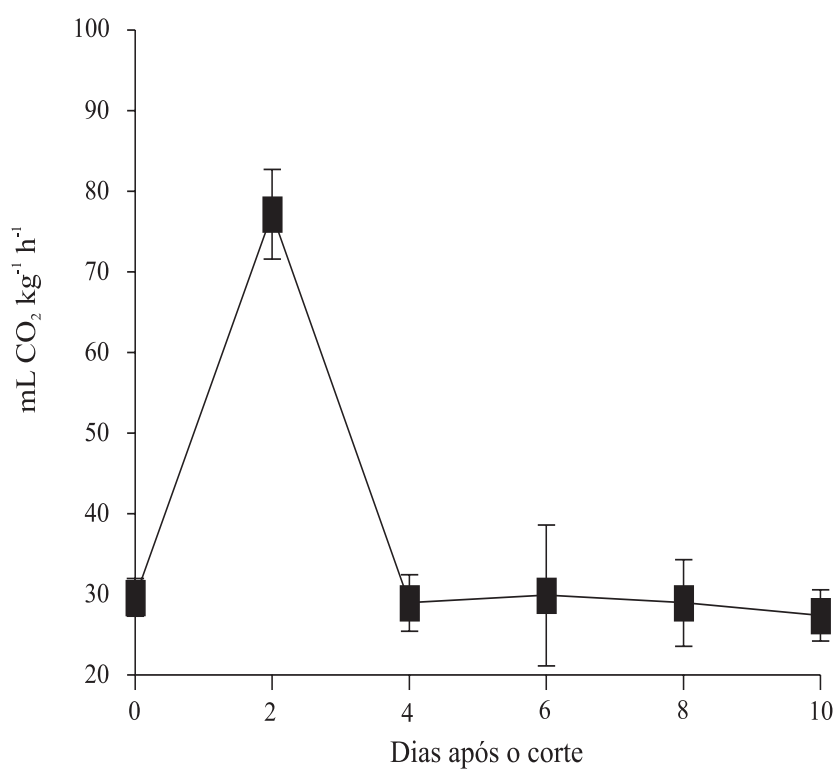

Figura 2. Taxa respiratória de beterrabas raladas durante o armazenamento a $5 \pm 1^{\circ} \mathrm{C}$ e $85 \pm 5 \%$ UR. Barras verticais representam o desvio-padrão da média. das, a produção de etileno nas primeiras horas após o corte atingiu valores de $0,90 \mu \mathrm{L} \mathrm{kg}^{-1} \mathrm{~h}^{-1}$ (Figura 3), com pouca variação ao longo das quatro horas de avaliação e durante o período de armazenamento.

De acordo com Sakr et al. (1997), o aumento da produção de etileno pode ser uma resposta hormonal e bioquímica resultante do estresse causado pelo corte. Isto ocorre porque o primeiro alvo desse estresse é a membrana plasmática, a qual responde com mudanças em suas características físicas, de forma a contornar tais perturbações e tentar reparar os danos causados durante o processamento.

A contagem inicial das bactérias psicrotróficas foi de aproximadamente $2,62 \times 10^{2} \mathrm{UFC} \mathrm{g}^{-1}$ (Tabela 1), ao passo que, no $10^{\circ}$ dia de armazenamento, as contagens aumentaram para valores próximos a $2,04 \times 10^{4} \mathrm{UFC} \mathrm{g}^{-1}$. Piagentini et al. (1997) relataram aumento na população de microrganismos psicrotróficos em repolho minimamente processado, de $10^{2}$ para $10^{5} \mathrm{UFC}^{-1}$ após quatro dias de armazenamento do produto a $4^{\circ} \mathrm{C}$. García-Gimeno \& Zurera-Cosano (1997) observaram aumento de $10^{5}$ para $10^{7} \mathrm{UFC}^{-1}$ na contagem de microrganismos psicrotróficos em amostras de saladas de hortaliças minimamente processadas após o armazenamento a $4^{\circ} \mathrm{C}$.

A contagem inicial de coliformes totais foi, em média, 1,8 $\mathrm{NMP} \mathrm{g}^{-1}$ de produto, enquanto que após 10 dias de armazenamento esta contagem aumentou em cerca de
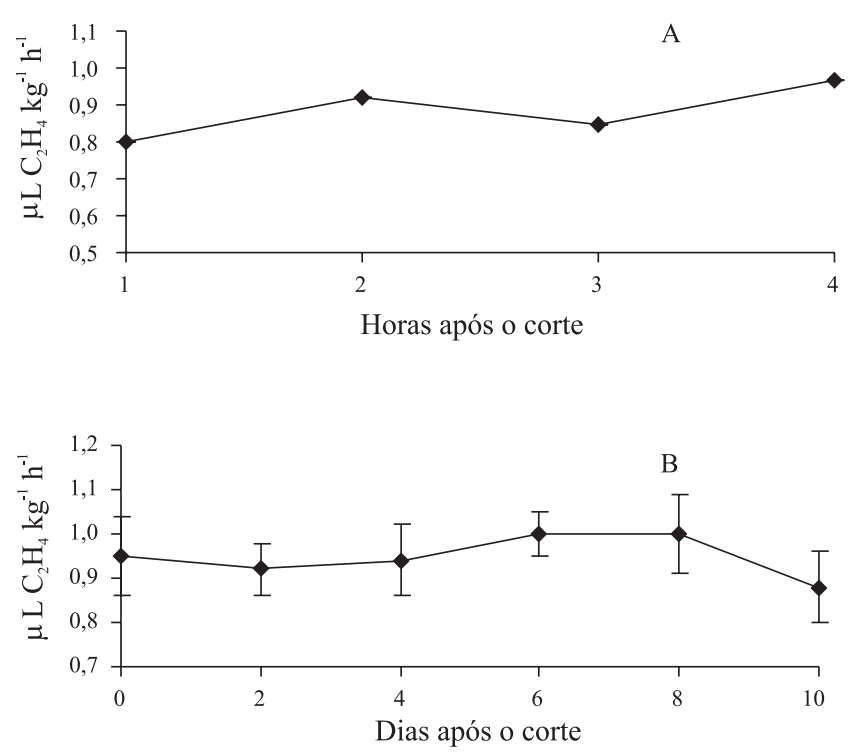

Figura 3. Taxa de síntese de etileno de beterrabas raladas logo após o corte (A) e durante o armazenamento (B) a $5 \pm 1^{\circ} \mathrm{C}$ e $85 \pm 5 \%$ UR. Barras verticais representam o desvio-padrão da média. 
20 vezes, alcançando valores em torno de 46 NMP g-1 de produto (Tabela 2 ).

Embora não existam, na legislação brasileira vigente, padrões para bactérias psicrotróficas totais e coliformes totais, tem sido preconizado que alimentos contendo contagens microbianas acima de $10^{5}$ e $10^{6} \mathrm{UFC} \mathrm{g}^{-1}$ podem ser impróprios para o consumo humano por causa da perda do valor nutricional, alterações organolépticas e riscos de contaminação. No presente trabalho, as amostras de beterrabas com dez dias de armazenamento apresentavam-se abaixo deste limite.

Em nenhuma das amostras de beterrabas analisadas houve detecção de coliformes fecais $\left(<0,3 \mathrm{NMP}^{-1}\right)$. Tais resultados colocam as amostras analisadas conforme o limite estabelecido pela Agência Nacional de Vigilância Sanitária (2001), de no máximo $10^{2}$ NMP de coliformes fecais $\mathrm{g}^{-1}$ de hortaliça fresca.

Não foi detectada a presença de Salmonella em nenhuma das repetições analisadas durante todo armazenamento.

Raízes intactas apresentaram uma taxa respiratória relativamente baixa em relação às beterrabas raladas. O mesmo pode ser observado na produção de etileno, que no caso de beterrabas intactas nem sequer foi detectado. Assim, operações de processamento mínimo,

Tabela 1. Contagem total de bactérias psicrotróficas, em beterrabas minimamente processadas armazenadas a $5 \pm 1^{\circ} \mathrm{C}$ e $85 \pm 5 \%$ UR, utilizando-se o método convencional $(\mathrm{PCA})^{(1)}$.

\begin{tabular}{ccc}
\hline Repetição & \multicolumn{2}{c}{ Dias após o corte } \\
\cline { 2 - 3 } & 0 & 10 \\
\hline 1 & $2,49 \times 10^{2}$ & $2,18 \times 10^{4}$ \\
2 & $2,90 \times 10^{2}$ & $2,26 \times 10^{4}$ \\
3 & $2,30 \times 10^{2}$ & $2,12 \times 10^{4}$ \\
4 & $2,62 \times 10^{2}$ & $1,75 \times 10^{4}$ \\
5 & $2,80 \times 10^{2}$ & $1,92 \times 10^{4}$ \\
\hline${ }^{(1)}$ Os dados representam as médias aritméticas das UFC g $^{-1}$ de produto.
\end{tabular}

${ }^{(1)}$ Os dados representam as médias aritméticas das $\mathrm{UFC}^{-1}$ de produto.

Tabela 2. Número mais provável de coliformes totais, em beterrabas minimamente processadas armazenadas a $5 \pm 1^{\circ} \mathrm{C}$ e $85 \pm 5 \%$ UR, utilizando-se o método dos tubos múltiplos ${ }^{(1)}$.

\begin{tabular}{ccc}
\hline Repetição & \multicolumn{2}{c}{ Dias após o corte } \\
\cline { 2 - 3 } & 0 & 10 \\
\hline 1 & 1,5 & 46 \\
2 & 1,5 & 46 \\
3 & 2,0 & 46 \\
4 & 2,0 & 46 \\
5 & 2,1 & 46 \\
\hline${ }^{(1)}$ Os dados representam o NMP de coliformes totais $\mathrm{g}^{-1}$ de produto.
\end{tabular}

principalmente descascamento e corte, ao elevar a taxa respiratória e a taxa de síntese de etileno de beterraba, contribuem para a redução na vida útil desta hortaliça minimamente processada. Como não foi observada a presença de coliformes fecais e de Salmonella nas amostras analisadas, fica demonstrada a eficácia dos cuidados higiênico-sanitários realizados durante as etapas de processamento do produto, enquadrando-o nos padrões microbiológicos vigentes no país.

\section{Conclusões}

1. A taxa respiratória e a produção de etileno aumentam com o processamento mínimo.

2. Condições higiênicas adequadas possibilitam a obtenção de um produto com padrão microbiológico de acordo com a legislação de alimentos, até o 10o dia de armazenamento.

\section{Agradecimentos}

À Fapesp, pelo suporte financeiro; à Capes, pela concessão de bolsa de mestrado; ao CNPq, pela concessão de bolsa de produtividade em pesquisa.

\section{Referências}

AGÊNCIA NACIONAL DE VIGILÂNCIA SANITÁRIA. Resolução - RDC nº12, de 2 de janeiro de 2001. Disponível em: <www.anvisa.gov.br/legis/resol/12_01rdc.htm> Acesso em: 21 fev. 2002.

ARRUDA, M.C. Processamento mínimo de melão rendilhado: tipo de corte, temperatura de armazenamento e atmosfera modificada. 2002. 71p. Dissertação (Mestrado) - Universidade de São Paulo, Escola Superior de Agricultura Luiz de Queiroz, Piracicaba.

BRECHT, J.K. Physiology of lightly processed fruits and vegetables. Hortscience, v.30, p.18-21, 1995.

CHITARRA, M.I.F. Processamento mínimo de frutos e hortaliças. Viçosa: Centro de Produções Técnicas, 1998. 88p.

CHERVIN, C.; TRIANTAPHYLIDES, C.; LIBERT, M.F.; SIADOUS, R.; BOISSEAU, P. Reduction of wound induced respiration and ethylene production in carrot root tissues by gamma irradiation. Postharvest Biology and Technology, v.2, p.7-17, 1992.

GARCÍA-GIMENO, R.M.; ZURERA-COSANO, G. Determination of ready-to-eat vegetable salad shelf-life. International Journal of Food Microbiology, v.36, p.31-38, 1997.

GUNES, G.; LEE, C.Y. Color of minimally processed potatoes as affected by modified atmosphere packaging and antibrowning agents. Journal of Food Science, v.62, p.572-582, 1997. 
INTERNATIONAL FRESH-CUT PRODUCE ASSOCIATION. Fresh-cut produce handling guidelines. $3^{\text {rd }}$ ed. Newark: Produce Marketing Association, 1999. 39p.

KASMIRE, R.F.; CANTWELL, M. Postharvest handling systems: underground vegetables (roots, tubers and bulbs). In: KADER, A.A. (Ed.). Postharvest technology of horticultural crops. Oakland: University of California, 1992. p.271-275.

LÓPEZ OSORNIO, M.M.; CHAVES, A.R. Quality changes in stored raw grated beetroots as affected by temperature and packaging film. Journal of Food Science, v.63, p.327-330, 1998.

MORETTI, C.L. Processamento mínimo de hortaliças: alternativa viável para a redução de perdas pós-colheita e agregação de valor ao agronegócio brasileiro. Horticultura Brasileira, v.17, p.1, 1999.

MORETTI, C.L.; SILVA, W.L.; ARAUJO, A.L. Quality attributes and carbon dioxide evolution of bell peppers as affected by minimal processing and storage temperature. Proceedings of The Florida State Horticultural Society, v.113, p.156-159, 2000.

PIAGENTINI, A.M.; PIROVANI, M.E.; GÜEMES, D.R.; DI PENTIMA, J.H.; TESSI, M.A. Survival and growth of Salmonella hadar on minimally processed cabbage as influenced by storage abuse conditions. Journal of Food Science, v. 62, p.616-618, 1997.

PURVIS, A.C. The role of adaptive enzymes in carbohydrate oxidation by stressed and senescing plant tissues. HortScience, v.32, p.1165$1168,1997$.
SHAMAILA, M.; POWRIE, W.D.; SKURA, B.J. Sensory evaluation of strawberry fruit stored under modified atmosphere packaging (MAP) by quantitative descriptive analysis. Journal of Food Science, v.57, p.1168-1172, 1992.

SAKR, S.; NOUBAHNI, M.; BOURBOULOUX, A.; RIESMEIER, J.; FROMMER, W.B.; SAUER, N.; DELROT, S. Cutting, ageing and expression of plant membrane transporters. Biochimica et Biophysica Acta, v.1330, p.207-216, 1997.

SHEWFELT, R.L. Postharvest treatment for extending the shelf life of fruits and vegetables. Food Technology, v.40, p.70-80, 1986.

SILVA, N.; JUNQUEIRA, V.C.A.; SILVEIRA, N.F.A. Manual de métodos de análise microbiológica de alimentos. 2.ed. São Paulo: Varela, 2001. 317p.

VANDERZANT, C.; SPLITTSTOESSER, D.F. Compendium of methods for the microbiological examination of foods. $3^{\text {rd }}$ ed. Washington: APHA, 1992. 1219p.

WATADA, A.E.; ABE, K.; YAMUCHI, N. Physiological activities of partially processed fruits and vegetables. Food Technology, v.44, p.116-122, 1990.

WILEY, R.C. (Ed.). Minimally processed refrigerated fruits and vegetables. New York: Chapman \& Hall, 1994. 368p.

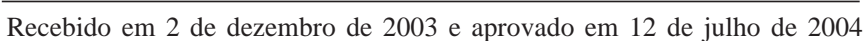

